\title{
Prevalence of hepatitis $C$ infection among the general population and high-risk groups in the EU/EEA: a systematic review update
}

Ru Han ${ }^{1,2^{*}}$ (D) Junwen Zhou ${ }^{1,2}$, Clément François ${ }^{1,2}$ and Mondher Toumi ${ }^{1,2}$

\begin{abstract}
Background: Although significant improvement in efficacy measured by a sustained virological response, the high acquisition costs of direct-acting antivirals limit the access for patients and influence the costs of healthcare resource utilisation in hepatitis C. It is important to have the latest estimates of prevalence, especially in high-risk groups, for cost of illness, cost-effectiveness and budget impact studies.

Methods: Original studies on the estimates of the prevalence among general and high-risk groups in the European Union/European Economic Area (EU/EEA) were retrieved from Medline and Embase for the period from 2015 to 2018. All included studies were evaluated for risk of selection bias and summarised together in a narrative form. Results from previous reviews and updated searches were compared per country among different populations, respectively.

Results: Among the 3871 studies identified, 46 studies were included: 20 studies were used for the estimate of the general population; 3 for men who have sex with men (MSM); 6 for prisoners; and 17 for people who inject drugs (PWID). Compared with the results reported in previous systematic reviews, the updated estimates were lower than previously in most available countries. Anti-HCV general population prevalence estimates ranged from 0.54 to $1.50 \%$ by country. The highest prevalence of anti-HCV was found among PWID (range of 7.90-82.00\%), followed by prisoners (7.00-41.00\%), HIV-positive MSM (1.80-7.10\%), HIV-negative MSM (0.20-1.80\%), pregnant women (0.10-1.32\%) and first-time blood donors (0.03-0.09\%).

Conclusions: Our study highlights the heterogeneity in anti-HCV prevalence across different population groups in EU/EEA. The prevalence also varies widely between European countries. There are many countries that are not represented in our results, highlighting the need for the development of robust epidemiological studies.
\end{abstract}

Keywords: Hepatitis C, Prevalence, Europe, People who inject drugs, Men who have sex with men, Prisoners, High-risk groups, Systematic review

\section{Background}

Infection with hepatitis $\mathrm{C}$ virus (HCV) leads to an asymptomatic acute stage. However, approximately $75 \%$ of acutely infected patients face a substantial risk of developing chronic HCV infection [1]. During the 2 decades after infection, 27\% develop liver cirrhosis, and 25\% develop hepatocellular carcinoma (HCC) $[2,3]$. Worldwide, an estimated 71 million people were living with chronic $\mathrm{HCV}$

\footnotetext{
* Correspondence: rha@creativ-ceutical.com

${ }^{1}$ University of Aix-Marseille, Marseille, France

${ }^{2}$ Creativ-Ceutical, 215, rue de Faubourg St-Honoré, 75008 Paris, France
}

infection (1.0\% of the global population) [4]. Whilst, in the European Union/European Economic Area (EU/EEA), it was estimated that more than 14 million people were living with chronic $\mathrm{HCV}$ infection, suggesting a relatively higher prevalence of $1.5 \%$ in this region [4].

Given to the slow rates of liver disease progression, many countries are yet to experience the full burden of HCV-related disease [5]. However, decade-long delays between infection and the expression of chronic liver disease or liver cancer made it difficult to link these diseases to earlier $\mathrm{HCV}$ infections. Reliable and timely

(c) The Author(s). 2019 Open Access This article is distributed under the terms of the Creative Commons Attribution 4.0 International License (http://creativecommons.org/licenses/by/4.0/), which permits unrestricted use, distribution, and reproduction in any medium, provided you give appropriate credit to the original author(s) and the source, provide a link to the Creative Commons license, and indicate if changes were made. The Creative Commons Public Domain Dedication waiver (http://creativecommons.org/publicdomain/zero/1.0/) applies to the data made available in this article, unless otherwise stated. 
prevalence data is therefore important to describe the current burden of the disease.

Most people infected with $\mathrm{HCV}$ remain unaware of their infection. The hidden burden estimated, based on limited data from the EU/EEA, shows that less than 15\% of those chronically infected with $\mathrm{HCV}$ are aware of their diagnosis [6-8]. An anti-HCV antibodies serology test is recommended by the European Association for the Study of the Liver (EASL), as the first-line diagnostic test for HCV screening, which is evident of the past or current $\mathrm{HCV}$ infection [9]. If the result is positive, then the current infection should be confirmed by a sensitive RNA test. Anti-HCV antibodies are detectable by enzyme immunoassay (EIA) in the vast majority of patients with an $\mathrm{HCV}$ infection. In addition, rapid diagnostic tests (RDTs) are also recommended in settings where there is limited access to laboratory infrastructure and testing or populations where access to RDTs would facilitate linkage to care [10]. The primary goal of diagnostic testing is to identify and link infected individuals to appropriate treatment. Several modelling studies suggest that scaling up an $\mathrm{HCV}$ treatment can lead to substantial reductions in anti-HCV prevalence and reduce transmission [11-14]. The introduction of direct-acting antivirals (DAAs) has been a major breakthrough in the treatment of hepatitis C. However, the high acquisition costs of sofosbuvir-based regiments limit the access for patients and influence the costs of healthcare resource utilisation in hepatitis $C$ [15]. It is important to have the latest estimates of prevalence, especially in high-risk groups, for cost of illness, cost-effectiveness and budget impact studies.

This study chose the most published reviews with a low risk of selection bias, according to an overview of systematic reviews on clinical burden of HCV infection [16]. This study updated 2 previous systematic reviews undertaken respectively among the general population [17] and highrisk groups [18] in 2015. In Europe, the high-risk groups for the acquisition of $\mathrm{HCV}$ include people who inject drugs (PWID), men who have sex with men (MSM) and people in prison. The aim of this study was to update and expand the estimates for anti-HCV prevalence.

\section{Objectives}

The objective of the study is to update the anti-HCV prevalence (the serologic markers used as proxies for chronic infection in this study) among the general population and high-risk populations (MSM, prisoners, and PWID).

\section{Methods}

\section{Date source and search strategy}

Original research studies on the estimates of the prevalence among general and high-risk populations in the EU/ EEA were retrieved from Medline and Embase for the period from 2015 to 2018. The search strategy used was consistent with previous reviews $[17,18]$ and is shown in Additional file 1. The search terms covered the following domains: disease-related (HCV infection), outcome-related (anti-HCV/HCV RNA prevalence), and geographic-related search terms (EU/EEA). Two separate searches were conducted to maximise the yield of the search, so that no population-specific search terms were included among the general population, MSM and prisoners. However, PWID-specific terms were included due to 2 reasons. The first being that previous reviews didn't conduct literature database searching, whilst the second was because the result of prevalence among PWID was only from the European Monitoring Centre for Drugs and Drug Addiction (EMCDDA). The relevant yield among PWID was much according to our preliminary search. To cover the complete time scope of the published studies the search for the general population, MSM and prisoners was limited to records between January 2015 and December 2018 and the search for PWID was limited between January 2009 and December 2018.

\section{Inclusion/exclusion criteria and data extraction}

The inclusion/exclusion criteria $[17,18]$ considered population, outcomes of interest, study designs, publication timeframe, and geographical scope. Studies were included if they: 1) reported anti-HCV seroprevalence among the general population, pregnant women, first-time blood donors, PWID, MSM, or prisoners; 2) measured the actual presence of viral markers (anti-HCV antibody in this study) in bodily fluid or dried blood spot samples in human subjects; 3 ) reported original data; 4) were published after 2015 to the present among the general population, pregnant women, first-time blood donors, MSM, or prisoners and published after 2009 to the present among PWID; 5) reported outcomes in one or more EU/EEA member states or any of their regions. Studies were excluded if they 1) targeted non-representative populations, e.g. the homeless, migrants, patients with specific diseases etc.; 2) did not report specified serological markers, or the reported study was not conducted on humans or only a self-reported/unconfirmed prevalence; 3) reported modelled or extrapolated data only, or opinion papers, editorials, guidelines or recommendations, correspondence articles, systematic reviews or meta-analysis; 4) were published out the targeted timeframe; 5) reported data on non-EU/EEA countries only. More details on the inclusion/exclusion criteria are shown in Additional file 1.

The extraction form included year, country, characteristics of the analysed population, the sampling method, laboratory test used, participation rate, number of participants, and anti-HCV results. For studies reporting the prevalence in MSM, data on HIV sero-status was also extracted. 


\section{Quality assessment for risk of selection bias}

Each included study was evaluated for risk of selection bias using frameworks developed by Hofstraat et al. and Falla et al. $[17,18]$. For studies among the general population and prisoners, three domains were included: whether estimates were standardised by age and sex, the representativeness of sampling (e.g. random vs. convenience sampling) and geographical coverage. For PWID and MSM studies, just one domain was included: geographical coverage. Points were awarded in each domain for a lower risk of bias, and a total score calculated by summing the values in each domain. An estimate among the general population and prisoners was considered of low risk when it reached a study quality score $\geq 4$. A low risk estimate of prevalence in PWID and MSM was defined as a study quality score $\geq 1$.

\section{Data analysis}

All included studies were summarised together in a narrative form and in summary tables that tabulate the important description of the study population, recruiting period, results and study quality. According to the results of the systematic review previously performed, an algorithm was applied to different populations separately $[17,18]$ : If a single low risk of selection bias prevalence estimate was available for a country, this was used. If a low risk of selection bias estimate was not available, high risk of selection bias estimates were used (these were pooled when possible). Data per country were pooled according to the standard error and sample size. Then $95 \%$ confidence intervals were calculated by the estimated average and pooled sample size. Results of subgroup analyses of age-specific, gender-specific, or injecting risk-specific prevalence were reported. Results from previous reviews and the updated searches were compared per country among different populations, respectively.

The overall population was categorised into 2 groups: (1) the general population, inclusive of susceptible population with no recognised risk factors for reinfection (communities, screening participants, pregnant women, and first-time blood donors); (2) high-risk populations, inclusive of susceptible MSM, prisoners, and PWID. The majority of EU/EEA countries offer antenatal $\mathrm{HCV}$ screening and first-time blood donors screening. These 2 subgroups among the general population are the most complete population prevalence source and used as a proxy population [17]. However, we conducted separate analysis between pregnant women, first-time blood donors and other general populations because the previous systematic review reported that they are not representative enough.

Some estimates among the general population included exclusively multiple subgroups, overlapping with high-risk populations. When pooled together, however, the subgroup data were excluded and pooled with the relevant high-risk populations based on the results of quality assessment.

\section{Results \\ Literature search retrievals}

The search for data on anti-HCV prevalence in the general population and MSM, and people in prison and PWID identified 2790 and 1081 citations, respectively. After the title/abstract screening, 73 articles for the general population with 2 subgroups and 26 articles for PWID were included. Following the full text screening of these 99 papers, 53 publications were considered not relevant. Finally, 46 publications were included in the review of prevalence data, with 11 publications used for the estimate of the general population, 7 for pregnant women, 2 for first-time blood donors, 3 for MSM, 6 for prisoners and 17 for PWID (Fig. 1). The results of quality assessment for risk of selection bias are shown in Additional file 1.

\section{Anti-HCV prevalence among the general population in EU/EEA \\ General population}

The anti-HCV general population prevalence estimates were found for 7 of the 34 countries in our review, ranging from 0.54 to $1.50 \%$ by country (Table 1 ). More than one estimate was available for 4 countries of the 7 countries covered, with the most estimates for Spain $(n=3)$. Eight low risk of selection bias estimates from 5 countries (Czech Republic, Ireland, Italy, Portugal and Spain) were available. Multiple low-risk of selection bias estimates were available for a pooled estimate in Italy $(n=2)$. A relatively high anti-HCV prevalence was found in the Czech Republic (1.67\%), Poland (1.50\%) and Italy (1.37\%). The estimate for Poland, however, is based on one single study with a high risk of selection bias $($ score $=2$ ). The other article reporting the prevalence estimate on the general female population in Poland was not pooled. Three estimates were available for Spain, of which only one was of low risk of selection bias and reported an anti-HCV prevalence of $1.11 \%$. One article reported $1.14 \%$ in the Callosa D'En Sarrià and Valencian Region. The other one reported $0.60 \%$ in the general female population. Subgroup analysis of age-specific prevalence was available for Italy $[22,23]$ and Poland [24]. In Italy $[22,23]$, the prevalence of $\mathrm{HCV}$ increased with an increasing birth cohort $(0.20 \%$ in subjects born after the year $1984,1.20 \%$ in those born in 1975-1984, 1.60\% in those born in 1965-1974, $1.20 \%$ in those born in 1955-1964, 2.20\% in those born in $1945-1954,7.00 \%$ in those born in 1935-1944, and $4.20 \%$ in those born before the year 1953). In Poland [24], a higher prevalence was found in the post-reproductive population with an age more than 45 years $(1.50 \%$ in 


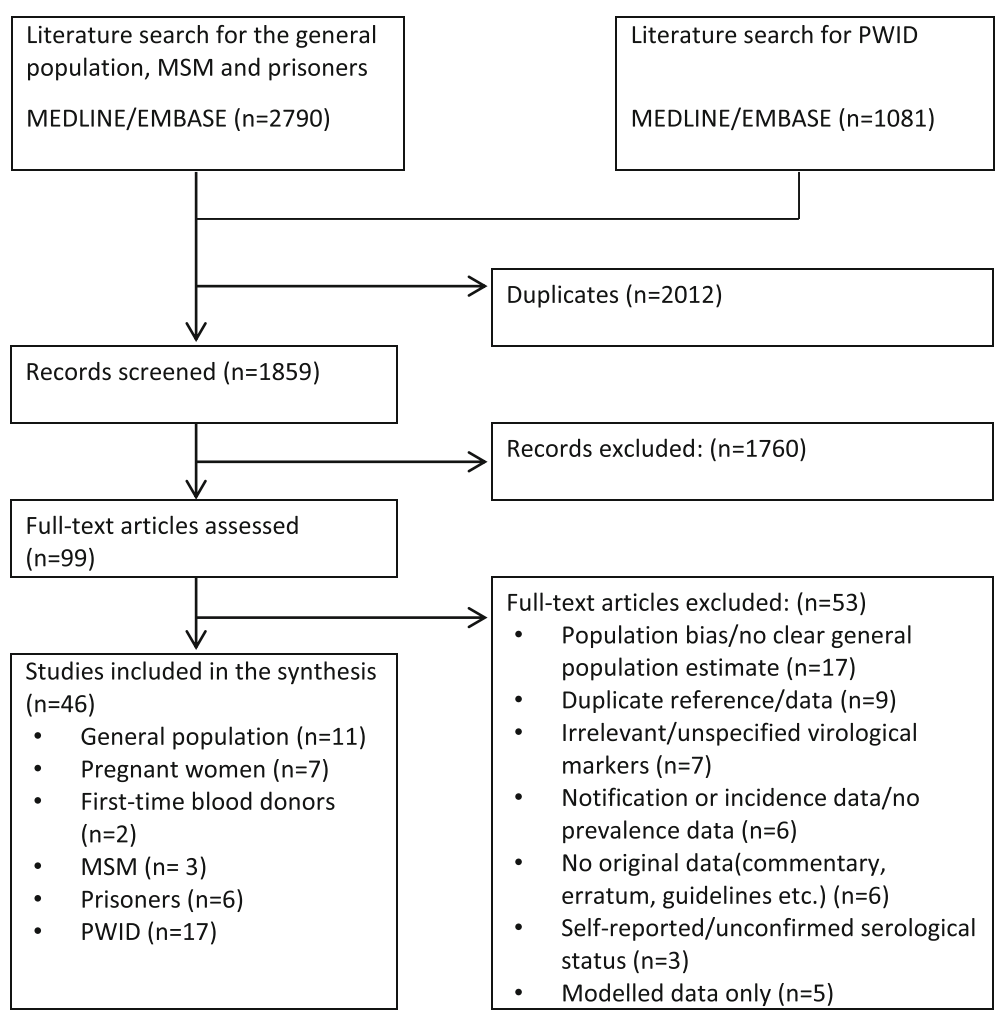

Fig. 1 Flow diagram of the study selection process

$15-24$ years, $1.20 \%$ in $25-34$ years, $1.60 \%$ in $35-44$ years, $2.90 \%$ in $45-54$ years and $2.60 \%$ in $55-64$ years).

\section{Pregnant women}

An estimate of antenatal anti-HCV prevalence was found for 6 of the 34 countries in our review, ranging from 0.10 to $1.32 \%$ by country (Table 2). More than one estimate was available only for the UK of the 6 countries covered $(n=2)$. Five low risk of selection bias estimates from 5 countries (Poland, Slovenia, Spain, Sweden and the UK) were available. Only the estimate of Italy was of high risk of selection bias. Relatively high anti-HCV prevalence was found in Poland (1.32\%) and Spain $(0.55 \%)$. Relatively low prevalence was reported in the UK $(0.10 \%)$. The other article reporting the prevalence estimate on women who attended antenatal clinics in London $(0.5 \%)$ was not pooled given to the potential geographic bias. Subgroup analysis of age-specific prevalence was available for the UK [30, 31], Poland [34] and Slovenia [32]. In the UK $[30,31]$, the antenatal anti$\mathrm{HCV}$ prevalence increased with increasing age in mothers born in the UK $(0.00 \%$ in younger than 21 years, $0.00 \%$ in $21-25$ years, $0.00 \%$ in $26-30$ years, $0.03 \%$ in $31-35$ years and $0.07 \%$ in older than 35 years) and Asia-Pacific $(0.00 \%$ in younger than 21 years, $0.00 \%$ in $21-25$ years, $0.12 \%$ in $26-30$ years, $0.16 \%$ in $31-35$ years and $0.49 \%$ in older than 35 years), but peaked in mothers of $26-30$ years $(0.85 \%)$ born in Eastern Europe $(0.00 \%$ in younger than 21 years, $0.22 \%$ in $21-25$ years, $0.16 \%$ in $31-35$ years and $0.29 \%$ in older than 35 years). No statistically significant differences in antenatal anti-HCV prevalence between age groups were reported in Poland (0.90\% in $15-24$ years, $0.70 \%$ in $25-34$ years and $0.80 \%$ in $35-44$ years) [34] and Slovenia $(0.00 \%$ in younger than 20 years, $0.07 \%$ in $20-29$ years and $0.05 \%$ in older than 30 years) [32].

\section{First-time blood donors}

An estimate of anti-HCV prevalence in first-time blood donors was available for only 2 of the 34 countries in our review, with Greece reporting $0.03 \%$ and Italy reporting $0.09 \%$ (Table 2). One high risk of selection bias estimate for Greece and one low risk of selection bias estimate for Italy were available. There is no subgroup analysis among first-time blood donors reported.

\section{Anti-HCV prevalence among high-risk populations in the EU/EEA \\ MSM}

An estimate of anti-HCV prevalence in MSM was found for 3 of the 34 countries in our review (Table 3). Furthermore, the MSM was divided into 2 categories: HIVpositive MSM and HIV-negative MSM. The prevalence in HIV-positive MSM covered 3 countries, ranging from 


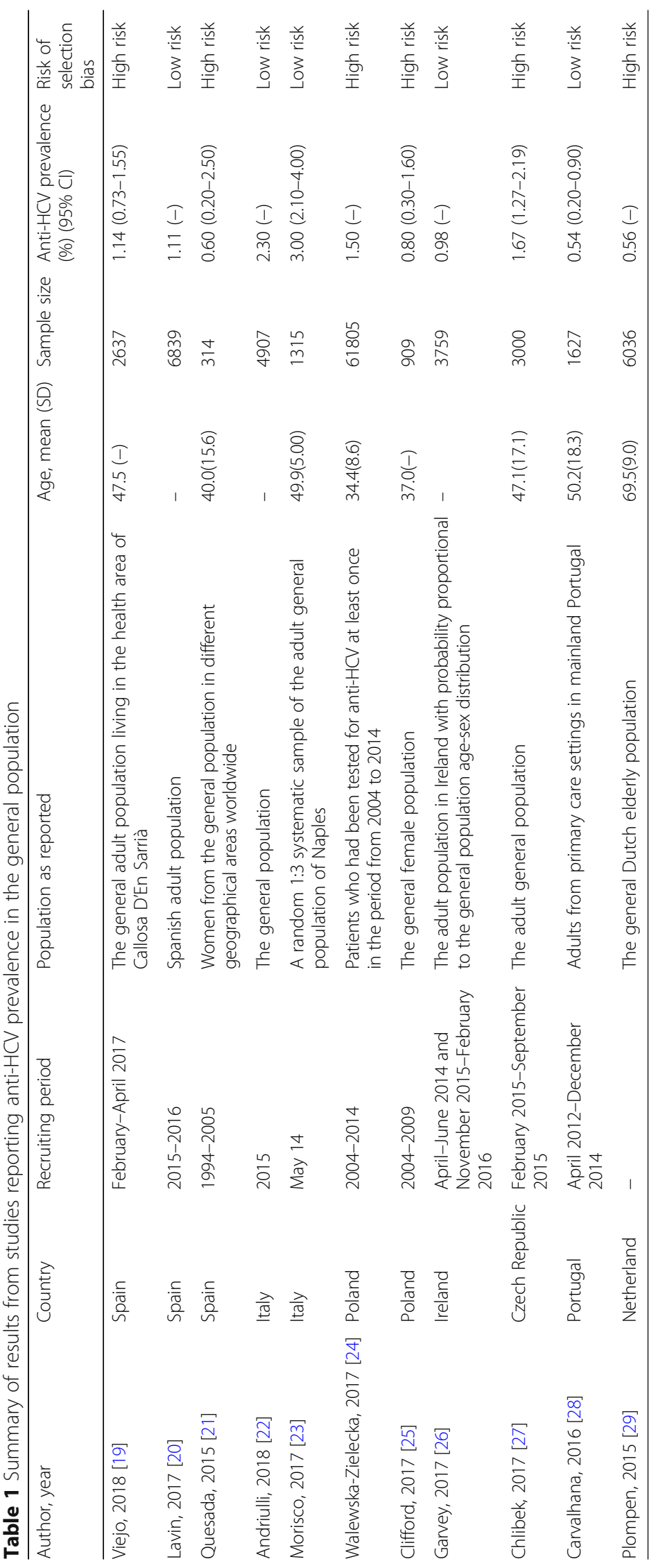




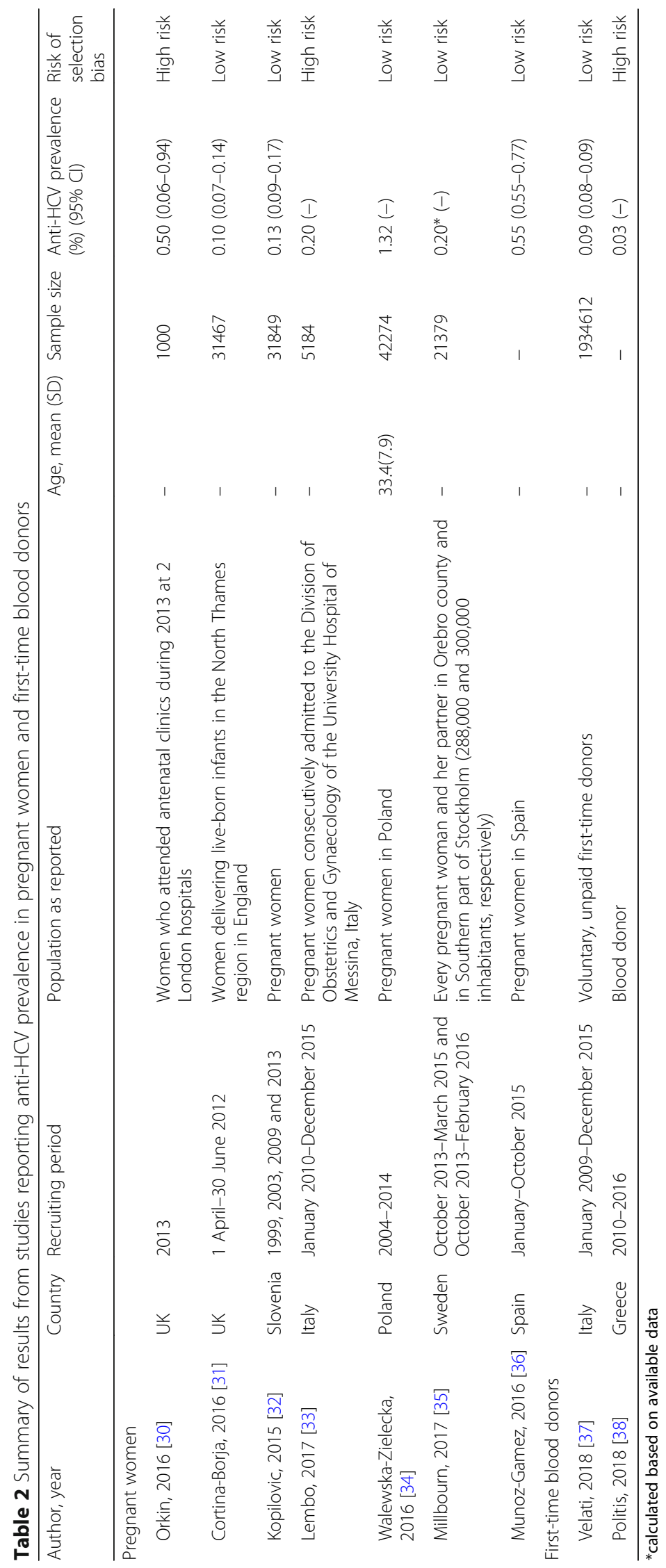




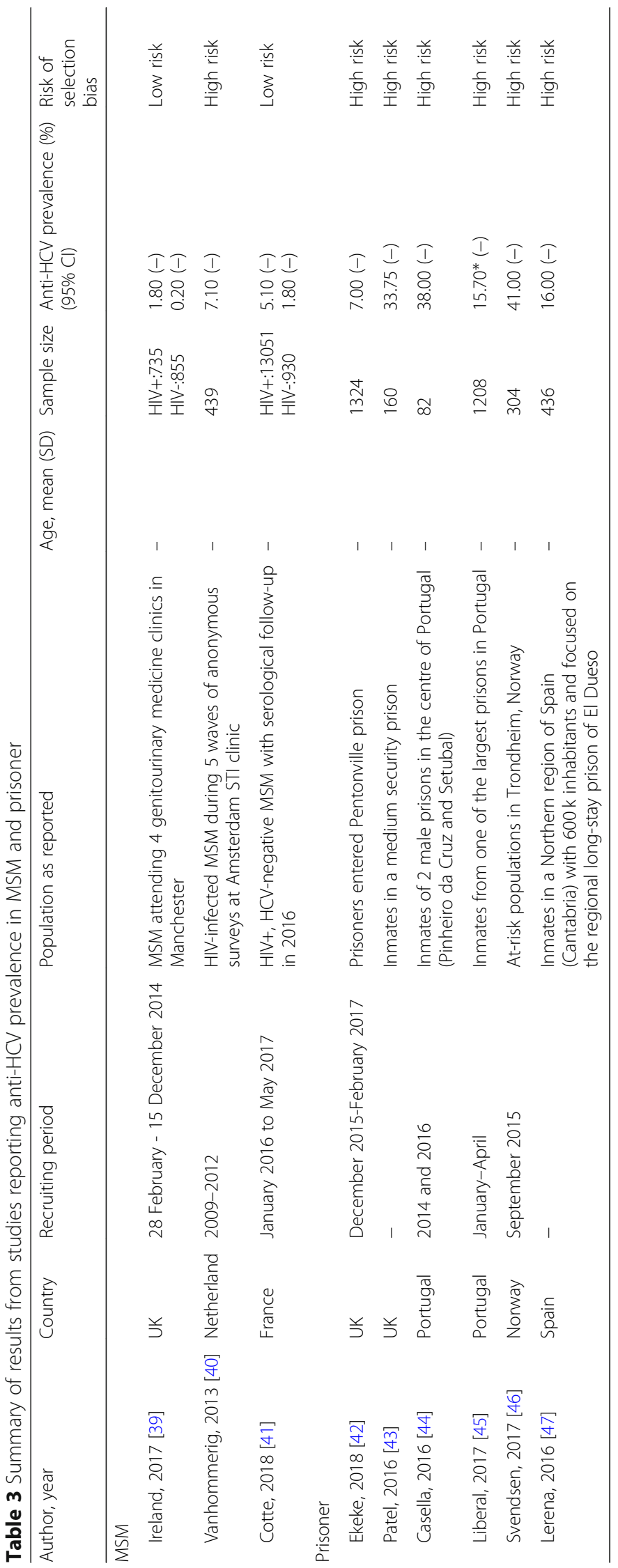


$1.80 \%$ (the UK) to $7.10 \%$ (the Netherlands). The other country, France, reported $5.10 \%$. The prevalence in HIVnegative MSM covered 2 countries, ranging from $0.20 \%$ (the UK) to $1.80 \%$ (France). Two low risk of selection bias estimates from 2 countries (the UK and France) were available. Only the estimate of the Netherlands was of high risk of selection bias. There is no subgroup analysis among MSM reported.

\section{Prisoners}

An estimate of anti-HCV prevalence was found for 4 of the 34 countries in our review, ranging from 7.00 to $41.00 \%$ by country (Table 3 ). More than one estimate was available for the UK $(n=2)$ and Portugal $(n=2)$ of the 4 countries covered. All estimates in prisoners were of high risk of selection bias. All studies were singlecentre in a regional level, except the one in Portugal, which was a multi-centre. Three studies reported a ratio of sex with more males than females. The other 3 studies did not report a ratio of sex. None of these 6 studies reported data on age. The studies in Portugal and Spain used exhaustive sampling in the included prison. Sampling method for the other studies was not reported. An extremely high prevalence was found in Norway (41.00\%). However, this estimate was from a single high risk of selection bias study with a small sample size $(n=62)$. There is no subgroup analysis among prisoners reported.

\section{PWID}

An estimate of anti-HCV prevalence was found for 13 of the 34 countries in our review, ranging from 7.90 to $82.00 \%$ by country (Table 4 ). More than one estimate was available for 4 of 13 countries covered, with the most estimates for the UK $(n=3)$. Nine low risk of selection bias estimates from 6 countries (Croatia, Hungary, Germany, France, Spain and the UK) were available. Multiple low risk of selection bias estimates were available for a pooled estimate in the UK $(n=3)$ and France $(n=2)$. A high anti$\mathrm{HCV}$ prevalence was found in Sweden (82.00\%) and Spain $(72.00 \%)$. A relatively low prevalence was reported in the UK (36.50\%) and Croatia (34.04\%). However, the estimate in Spain was of high risk of selection bias (score $=0)$. One article in the UK covered the vulnerable population in London, including both PWID and prisoners. Based on the results of quality assessment $($ score $=1)$, this result was also pooled into the estimate. Another article in the UK reported only a subgroup prevalence based on the years when the subjects were born. However, the exact estimate of subjects who were born in the early 1990s was not available. Only estimates from the subjects born after 2000 were pooled. The article in Croatia reported separated prevalence among PWID in the cities of Zagreb, Split and Rijeka. Data from the 3 cities in this article were pooled. The same situation came up in Germany with separated prevalence estimates in native German and former Soviet Union migrants, which were in the same article and pooled together. Subgroup analysis of age-specific prevalence was available for France [54] and Greece [56] and subgroup analysis of injection risk-specific prevalence was available for Greece [56], the UK [50], Hungary [58], and Spain [52]. Anti-HCV prevalence among PWID increased with increasing age in France $(15.00 \%$ in $18-35$ years and $56.00 \%$ in $35-65$ years) [54] and Greece (52.60\% in $15-24$ years and $90.00 \%$ in older 65 years) [56]. Longterm injectors (those who had been injecting for more than 5 years) reported higher anti-HCV prevalence than new injectors in Greece $(85.70 \%$ vs. $34.00 \%)$ [56], the UK $(60.00 \%$ vs. $38.00 \%)$ [50] and Spain $(77.10 \%$ vs. $59.40 \%)$ [52]. In Hungary [58], the anti-HCV prevalence in new psychoactive substances (NPS) injectors became the highest among the three injector groups $(74.00 \%$ in NPS injectors, $59.00 \%$ in amphetamine injectors and $55.00 \%$ in opioid injectors).

\section{Comparison analysis}

Pooled estimates by population and by country based on the results of quality assessment were shown in Table 5 . Compared with the results reported in previous systematic reviews, our results updated the prevalence in Czech Republic, Poland, Portugal among the general population, Sweden and Spain among pregnant women, the Netherlands, the UK and France among MSM, France, Spain, Germany, Sweden and Bosnia and Herzegovina among PWID. Among the general population, the updated estimates were lower than previous ones in most available countries. A significant decrease in anti-HCV prevalence was shown in Italy (1.37\% vs. $5.90 \%)$.

Except for the Netherlands $(0.56 \%$ vs. $0.10 \%)$ and Ireland $(0.98 \%$ vs. $0.10 \%)$, prevalence increased. The same results were reported among high-risk populations, where prevalence in most countries decreased, except for the estimates among PWID in Hungary (48.24\% vs. 24.10\%).

\section{Discussion}

This review is the first one to integrate and contrast prevalence estimates across the general population and 3 key high-risk groups in the EU/EEA. This review describes the finding of 46 publications estimating anti$\mathrm{HCV}$ prevalence from 17 of the 34 EU/EEA countries, with 11 publications focusing on the general population, 7 on pregnant women, 2 on first-time blood donors, 3 on MSM, 6 on prisoners and 17 on PWID. In total, 48 estimates for anti-HCV prevalence were included, with 11 estimates of the general population, 7 estimates of pregnant women, 2 estimates of first-time blood donors, 5 estimates of MSM, 6 estimates of prisoners and 17 


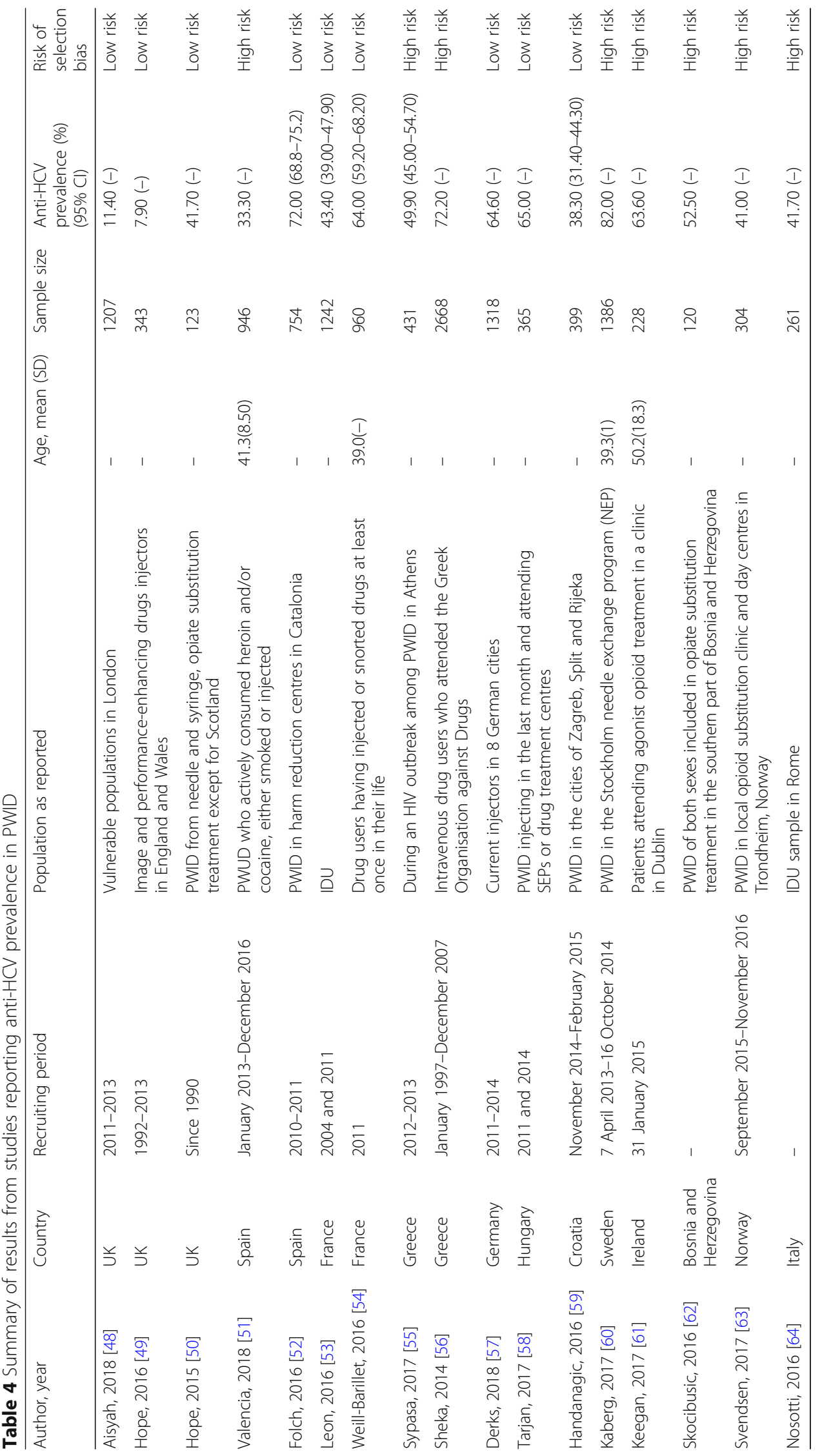


Table 5 Estimates of anti-HCV prevalence by population and by country

\begin{tabular}{|c|c|c|c|c|c|c|}
\hline Country & $\begin{array}{l}\text { Included } \\
\text { references }\end{array}$ & Selected references & Sample size & Anti-HCV prevalence (\%) $(95 \% \mathrm{Cl})$ & $\begin{array}{l}\text { Baseline } \\
\text { sample size }\end{array}$ & $\begin{array}{l}\text { Baseline prevalence (\%) } \\
(95 \% \mathrm{Cl})\end{array}$ \\
\hline \multicolumn{7}{|l|}{ General population } \\
\hline Spain & 3 & Single low risk & 13678 & $0.8(0.65-0.95)[20]$ & 364 & $1.1(0.3-2.8)[17]$ \\
\hline Italy & 2 & Pooled low risk & 12444 & $1.37(1.17-1.58)[22,23]$ & 4826 & $5.9(5.2-6.6)[17]$ \\
\hline Poland & 2 & Single high risk & 61805 & $1.5(1.4-1.6)[24]$ & - & - \\
\hline Czech Republic & 1 & Single low risk & 3000 & $1.67(1.21-2.13)[27]$ & - & - \\
\hline Portugal & 1 & Single low risk & 1627 & $0.54(0.18-0.9)[28]$ & - & - \\
\hline Netherlands & 1 & Single high risk & 6036 & $0.56(0.37-0.75)[33]$ & 4046 & $0.1(0.0-0.2)[17]$ \\
\hline Ireland & 1 & Single low risk & 3795 & $0.98(0.67-1.29)[26]$ & 1478 & $0.1(0.0-0.4)[17]$ \\
\hline \multicolumn{7}{|l|}{ Pregnant women } \\
\hline UK & 2 & Single low risk & 31467 & $0.1(0.06-0.13)[31]$ & 110621 & $1[17]$ \\
\hline Slovenia & 1 & Single low risk & 31849 & $0.13(0.09-0.17)$ [32] & 90 & $4.4[17]$ \\
\hline Italy & 1 & Single high risk & 5184 & $0.2(0.08-0.32)$ [33] & 10881 & $1.7(1.4-1.9)[17]$ \\
\hline Poland & 1 & Single low risk & 38309 & $0.76(0.67-0.85)[34]$ & 1534 & $0.1(0.0-0.3)[17]$ \\
\hline Sweden & 1 & Single low risk & 4112 & $0.27(0.11-0.43)[35]$ & - & - \\
\hline Spain & 1 & Single low risk & 21379 & $0.55(0.45-0.65)[36]$ & - & - \\
\hline \multicolumn{7}{|l|}{ First-time blood donors } \\
\hline Italy & 1 & Single low risk & 1934612 & $0.09(0.08-0.09)$ [37] & - & $0.094(0.085-0.104)$ [17] \\
\hline Greece & 1 & Single high risk & 3838919 & $0.03(0.03-0.03)$ [38] & - & $1.202(1.114-1.295)[17]$ \\
\hline \multicolumn{7}{|l|}{ MSM } \\
\hline Netherlands & 1 & Single high risk & 439 & $7.1(4.69-9.51)[40]$ & - & - \\
\hline UK & 1 & Single low risk & 1140 & $1.8(1.03-2.57)$ [39] & - & - \\
\hline France & 1 & Single low risk & 13051 & $5.1(4.72-5.48)[41]$ & - & - \\
\hline \multicolumn{7}{|l|}{ Prisoner } \\
\hline UK & 2 & Pooled high risk & 1484 & $7.9(6.53-9.28)[42,43]$ & 5450 & 17.7(16.4-18.4) [18] \\
\hline Portugal & 2 & Pooled high risk & 82 & $16.51(8.42-24.6)[44,45]$ & 151 & $34.4(26.9-42.6)[18]$ \\
\hline Norway & 1 & Single high risk & 62 & $51.6(39.06-64.14)$ [63] & & \\
\hline Spain & 1 & Single high risk & 436 & 16 (12.55-19.45) [47] & - & 22.7(18.3-27.1) [18] \\
\hline \multicolumn{7}{|l|}{ PWID } \\
\hline UK & 3 & Pooled low risk & 1818 & 36.5 (34.29-38.72) [48-50] & 3144 & 49.1 (47.4-50.9) [18] \\
\hline France & 2 & Pooled low risk & 3015 & $57.26(55.49-59.02)[53,54]$ & - & - \\
\hline Spain & 2 & Single low risk & 754 & $72(68.79-75.21)$ [52] & - & - \\
\hline Greece & 2 & Pooled high risk & 3099 & $69.67(68.05-71.29)[55,56]$ & 1309 & 68.1 (65.5-70.6) [18] \\
\hline Germany & 1 & $\begin{array}{l}\text { Pooled low risk from } \\
\text { a single study }\end{array}$ & 1526 & 66.18 (63.8-68.55) [57] & - & - \\
\hline Italy & 1 & Single high risk & 261 & $47.1(41.03-53.17)[64]$ & 743 & 60.5 (56.8-64.0) [18] \\
\hline Hungary & 1 & Single low risk & 755 & $48.24(44.67-51.81)[58]$ & 652 & 24.1 (20.8-27.6) [18] \\
\hline Croatia & 1 & $\begin{array}{l}\text { Pooled low risk from } \\
\text { a single study }\end{array}$ & 830 & $34.04(30.81-37.26)$ [59] & 200 & $44(37.0-51.2)[18]$ \\
\hline Sweden & 1 & Single high risk & 1386 & $82(79.98-84.02)$ [60] & - & - \\
\hline Ireland & 1 & Single high risk & 228 & $63.6(57.34-69.86)[61]$ & 200 & 41.5 (34.6-48.7) [18] \\
\hline Bosnia and Herzegovina & 1 & Single high risk & 120 & $52.5(43.53-61.47)$ [62] & - & - \\
\hline Norway & 1 & Single high risk & 304 & $41(35.46-46.54)$ [63] & 6342 & $63.0(61.8-64.2)$ \\
\hline
\end{tabular}


estimates of PWID. The anti-HCV prevalence varies widely between countries and populations.

For the majority of countries, the availability of estimates on the anti-HCV prevalence is limited. The estimates were reported in half of EU/EEA countries (17 of the 34). The results of quality assessment show there are potentially high risk of selection bias in half of available estimates (24 of the 48). The lack of low risk of selection bias prevalence estimates makes it challenging to gain an overview of the current epidemiological burden in the EU/EEA, especially in two high-risk groups, MSM and prisoners, with only 5 and 6 estimates included. Out of the stigma and reputational concerns, the access to MSM population is limited. The participation rate of screening in prison was high; however, the use of self-reported behavioral data and low sensitivity and specificity of laboratory test resulted in the limited inclusion of studies in prison environment.

This review confirms the diversity in anti-HCV prevalence among different populations. Compared with the prevalence among the general population, prevalence among first-time blood donors and pregnant women were found to be considerably lower, which agrees with the previous result that they are not a reliable proxy population to estimate prevalence in the general population. The prevalence among MSM, prisoners and PWID were found to be much higher than the corresponding prevalence in the general population. Of the high-risk groups considered, PWID reported the highest prevalence.

In contrast with most published systematic reviews, this study updates and adds new estimates of anti-HCV prevalence for three countries in the general population (Czech Republic, Poland and Portugal), for 2 countries in pregnant women (Spain and Sweden), for one country in MSM (the Netherlands), for one country in prisoners (Norway) and for 5 countries in PWID (Bosnia and Herzegovina, France, Germany, Spain and Sweden). Compared with previous estimates, the current estimates on prevalence among both the general and high-risk populations decreased in most available countries. While, the estimates of prevalence in the Netherlands [29] and Ireland [26] among the general population and in Hungary among PWID [58] increased. These estimates were all from single studies, and there may be a potential risk of selection bias. The estimate in the Netherlands was from a cohort consisting of more than 45-year-old elderly participants (mean age: 69.5 years) [29], which may lead to the relatively higher estimates than previous study (age of range: 15-44 years) [65]. The estimate in Ireland was from individuals whose specimens were submitted to the National Virus Reference Laboratory for diagnostic purpose, antenatal screening and pre-employment screening with most specimens being identified in older adults [26]. This was not likely to be completely representative of the general adult population and consequently led to higher estimates of prevalence. The estimate in Hungary was conducted among PWID attending drug treatment centres between 2011 and 2015 [58]. Since 2011, new psychoactive substances (NPS) have largely replaced traditionally injected drugs in Hungary [66]. NPS are unregulated products and have been associated with increases in injecting risks and HCV infection [66, 67]. High-risk environments for PWID may have played an important role in the increase of HCV prevalence in Hungary, especially for NPS injectors $[68,69]$. Another systematic review [70] reported the anti-HCV prevalence for the 20 WHO European Region countries outside the EU/EEA. The anti-HCV prevalence outside the EU/EEA was higher than inside the EU/EEA among the general population $(0.50-13.00 \%$ vs. 0.54 to $1.50 \%)$, and first-time blood donors $(0.03-6.40 \%$ vs. $0.03-0.09 \%)$, but lower among PWID (5.30-73.00\% vs. $7.90-82.00 \%$ ).

The strength of this review is that it covers all the general population and high-risk groups. The previous reviews, due to pragmatic reasons, extracted prevalence estimates for PWID from the data repository from the ECDDA. It is possible that this data set is not exhaustive. In our review update, however, PWID-specific search terms were used to identify potential studies. We believe that the description provided gives a sufficiently thorough review of recently published anti-HCV prevalence estimates. With the latest prevalence estimates, this study can contribute to the analyses in cost of illness, cost-effectiveness and budget impact to optimise the healthcare resource utilisation in hepatitis $\mathrm{C}$ management and a $\mathrm{HCV}$ eradication program in Europe. The fundamental approaches to control a HCV epidemic are prevention of new infections and management of existing infections. Currently, there is no vaccine for the prevention of the $\mathrm{HCV}$ infection. A needle/syringe provision (NSP) and opioid substitution treatment (OST) as the main primary prevention strategy and $\mathrm{HCV}$ antiviral treatment as a treatment-as-prevention strategy are the key components to reduce HCV prevalence. Several studies have shown that high coverage of NSP and OST [71-74] and scaling up HCV treatment, especially treatment with DAAs that possess high efficacy and improved safety profiles [11, 13, $14,75]$, can lead to substantial reductions in anti-HCV prevalence. The use of DAAs could make hepatitis $\mathrm{C}$ a rare disease in the next 20 to 30 years [76]. Despite advances in prevention and treatment, the HCV related disease burden is expected to increase before it starts declining, as well as corresponding healthcare cost [77]. This highlights the importance of optimisation of resource allocation in HCV eradication program.

However, this study confirmed that there was an evidence gap on anti-HCV prevalence among lots of EU/ 
EEA countries. This limitation of this study also provides the idea for further research. In some countries, no national studies had been reported, thus local and regional data were assumed to be reflective of the whole country. However, by assessing the methodological quality of the studies, this limitation can be further mitigated.

\section{Conclusion}

This review emphasises the heterogeneity in anti-HCV prevalence across different population groups in Europe. The prevalence also shows considerable diversity between EU/EEA countries. There are many countries that are not described in our results, emphasising the existing need to develop robust epidemiological studies.

\section{Additional file}

Additional file 1: Methodological details of study. 1.1 Search strategy for studies in Medline and Embase via Ovid; 1.2 Inclusion and exclusion criteria; 1.3 Results of quality assessment for risk of selection bias. (DOCX $95 \mathrm{~kb})$

\section{Abbreviations}

EMCDDA: European Monitoring Centre for Drugs and Drug Addiction; EU/ EEA: European Union/European Economic Area; HCV: Hepatitis C Virus; HIV: Human Immuno-deficiency Virus; MSM: Men Who Have Sex with Men; NPS: New Psychoactive Substance; NSP: Needle/syringe Provision; OST: Opioid Substitution Treatment; PRISMA: Preferred Reporting Items for Systematic Reviews and Meta-Analyses; PWID: People Who Inject Drugs; UK: United Kingdom

\section{Acknowledgements} Not applicable.

\begin{abstract}
Authors' contributions
HAR study concept and design, literature search, acquisition of data, analysis and interpretation of data, and drafting of the manuscript. ZHJ study concept and design, literature search, acquisition of data, analysis and interpretation of data, and critical revision of the manuscript for important intellectual content. FRC study concept and design, literature search, acquisition of data, interpretation of data, critical revision of the manuscript for important intellectual content, and supervision of the study. TOM study concept and design, literature search, analysis and interpretation of data, critical revision of the manuscript for important intellectual content, and supervision of the study. All authors have read and approved the final manuscript.
\end{abstract}

\section{Funding}

No funding for this study.

\section{Availability of data and materials}

The full search strategy, the inclusion/exclusion criteria and results on quality assessment of included studies are available in the Additional file 1.

\section{Ethics approval and consent to participate}

Not applicable.

\section{Consent for publication}

Not applicable.

\section{Competing interests}

The authors declare that they have no competing interests.
Received: 18 April 2019 Accepted: 12 July 2019

Published online: 23 July 2019

\section{References}

1. Grebely J, Dore GJ. What is killing people with hepatitis C virus infection? Semin Liver Dis. 2011:31:331-9.

2. Thein $H H$, Yi Q, Dore GJ, Krahn MD. Estimation of stage-specific fibrosis progression rates in chronic hepatitis $C$ virus infection. a meta-analysis and meta-regression. Hepatology. 2008;48:418-31.

3. Butt AA, Yan P, Lo Re V 3rd, Rimland D, Goetz MB, Leaf D, Freiberg MS, Klein $M B$, Justice $A C$, Sherman KE. Liver fibrosis progression in hepatitis $C$ virus infection after seroconversion. JAMA Intern Med. 2015;175:178-85.

4. World Health Organization. Global Hepatitis report, 2017. https://www.who. int/hepatitis/publications/global-hepatitis-report2017/en/. Accessed 1 Jan 2019

5. Razavi H, Waked I, Sarrazin C, Myers RP, Idilman R, Calinas F, Vogel W, Mendes Correa MC, Hezode C, Lazaro P, et al. The present and future disease burden of hepatitis $\mathrm{C}$ virus ( $\mathrm{HCV}$ ) infection with today's treatment paradigm. J Viral Hepat. 2014;21(Suppl 1):34-59.

6. Mathurin P. HCV burden in Europe and the possible impact of current treatment. Dig Liver Dis. 2013:45 Suppl 5:S314-7.

7. Mitchell AE, Colvin HM, Palmer Beasley R. Institute of Medicine recommendations for the prevention and control of hepatitis $B$ and $C$. Hepatology. 2010;51:729-33.

8. Papatheodoridis G, Thomas HC, Golna C, Bernardi M, Carballo M, Cornberg M, Dalekos G, Degertekin B, Dourakis S, Flisiak R, et al. Addressing barriers to the prevention, diagnosis and treatment of hepatitis $B$ and $C$ in the face of persisting fiscal constraints in Europe. report from a high level conference. J Viral Hepat. 2016;23(Suppl 1):1-12.

9. EASL Clinical Practice Guidelines. Management of hepatitis C virus infection. J Hepatol. 2014:60:392-420.

10. Easterbrook PJ. Who to test and how to test for chronic hepatitis $C$ infection - 2016 WHO testing guidance for low- and middle-income countries. J Hepatol. 2016;65:S46-s66.

11. de Vos AS, Prins M, Kretzschmar ME. Hepatitis C virus treatment as prevention among injecting drug users. who should we cure first? Addiction. 2015;110:975-83.

12. Hellard M, Rolls DA, Sacks-Davis R, Robins G, Pattison P, Higgs P, Aitken C, McBryde $E$. The impact of injecting networks on hepatitis $C$ transmission and treatment in people who inject drugs. Hepatology. 2014;60:1861-70.

13. Martin NK, Hickman M, Hutchinson SJ, Goldberg DJ, Vickerman P. Combination interventions to prevent HCV transmission among people who inject drugs. modeling the impact of antiviral treatment, needle and syringe programs, and opiate substitution therapy. Clin Infect Dis. 2013; 57(Suppl 2):S39-45.

14. Martin NK, Vickerman P, Grebely J, Hellard M, Hutchinson SJ, Lima VD, Foster GR, Dillon JF, Goldberg DJ, Dore GJ, Hickman M. Hepatitis C virus treatment for prevention among people who inject drugs. Modeling treatment scale-up in the age of direct-acting antivirals. Hepatology. 2013;58:1598-609.

15. Han R, Zhou J. PIN19 - A cost comparison of treating chronic hepatitis C patients with sofosbuvir-based regimens. Value Health. 2018;21:S224

16. Han R, Zhou J. PIN11 -Comparison of clinical burden of hcv infection between asia and europe. an overview of systematic review. Value Health. 2018;21:S63.

17. Hofstraat SHI, Falla AM, Duffell EF, Hahne SJM, Amato-Gauci AJ, Veldhuijzen IK, Tavoschi L. Current prevalence of chronic hepatitis B and $C$ virus infection in the general population, blood donors and pregnant women in the EU/EEA a systematic review. Epidemiol Infect. 2017:145:2873-85.

18. Falla AM, Hofstraat SHI, Duffell E, Hahne SJM, Tavoschi L, Veldhuijzen IK. Hepatitis $B / C$ in the countries of the EU/EEA. a systematic review of the prevalence among at-risk groups. BMC Infect Dis. 2018;18:79.

19. Gomez-Escolar Viejo L, Garcia Herola A, Saez Lloret I, Sanchez Ruano F, Clemente Paulino I, Quilez Ivorra C, Almenta Saavedra I, Martinez Perez D, Valverde de la Osa J. Screening of hepatitis C virus infection in adult general population in Spain. Eur J Gastroenterol Hepatol. 2018;30:1077-81.

20. Lavin AC, Perello C, Llerena S, Gomez M, Escudero MD, Rodriguez L, Estebanez A, Gamez B, Puchades L, Cabezas J, et al. Prevalence of hepatitis $C$ in the spanish population. The prevhep study (ethon cohort). J Hepatol. 2017:66:S272.

21. Quesada P, Whitby D, Benavente Y, Miley W, Labo N, Chichareon S, Trong $\mathrm{N}$, Shin HR, Anh PT, Thomas J, et al. Hepatitis C virus seroprevalence in the general female population from 8 countries. J Clin Virol. 2015;68:89-93. 
22. Andriulli A, Stroffolini T, Mariano A, Valvano MR, Grattagliano I, Ippolito AM, Grossi A, Brancaccio G, Coco C, Russello M, et al. Declining prevalence and increasing awareness of HCV infection in Italy. A population-based survey in five metropolitan areas. Eur J Intern Med. 2018;53:79-84.

23. Morisco F, Loperto I, Stroffolini T, Lombardo FL, Cossiga V, Guarino M, De Feo A, Caporaso N. Prevalence and risk factors of HCV infection in a metropolitan area in southern Italy. Tail of a cohort infected in past decades. J Med Virol. 2017:89:291-7.

24. Walewska-Zielecka B, Religioni U, Juszczyk G, Wawrzyniak ZM, Czerw A, Soszyński P, Fronczak A. Anti-hepatitis C virus seroprevalence in the working age population in Poland, 2004 to 2014. Euro Surveill. 2017;22(2):30441. https://doi.org/10.2807/1560-7917.ES.2017.22.2.30441. PubMed PMID: 28106526; PubMed Central PMCID: PMC5404489.

25. Clifford GM, Waterboer T, Dondog B, Qiao YL, Kordzaia D, Hammouda D, Keita N, Khodakarami N, Raza SA, Sherpa AT, et al. Hepatitis C virus seroprevalence in the general female population of 9 countries in Europe, Asia and Africa. Infect Agent Cancer. 2017:12:9.

26. Garvey P, O'Grady B, Franzoni G, Bolger M, Irwin Crosby K, Connell J, Burke D, De Gascun C, Thornton L. Hepatitis C virus seroprevalence and prevalence of chronic infection in the adult population in Ireland: a study of residual sera, April 2014 to February 2016. Euro Surveill. 2017;22(30):30579. https://doi.org/10.2807/1560-7917.ES.2017.22.30.30579. PubMed PMID: 28797323; PubMed Central PMCID: PMC5553053.

27. Chlibek R, Smetana J, Sosovickova R, Gal P, Dite P, Stepanova V, Pliskova L, Plisek S. Prevalence of hepatitis $C$ virus in adult population in the Czech Republic - time for birth cohort screening. PLoS One. 2017;12:e0175525.

28. Carvalhana SC, Leitao J, Alves AC, Bourbon M, Cortez-Pinto H. Hepatitis B and $C$ prevalence in Portugal: disparity between the general population and high-risk groups. Eur J Gastroenterol Hepatol. 2016;28:640-4.

29. Plompen EP, Maan R, de Knegt RJ, Taimr P, Hofman A, Stricker BH, Darwish Murad S, Janssen HL. P1286. Low prevalence of positive viral serology for HBV and HCV among a general dutch elderly population. Results from the rotterdam study. J Hepatol. 2015;62:S841.

30. Orkin C, Jeffery-Smith A, Foster GR, Tong CY. Retrospective hepatitis C seroprevalence screening in the antenatal setting-should we be screening antenatal women? BMJ Open. 2016;6:e010661.

31. Cortina-Borja M, Williams D, Peckham CS, Bailey H, Thorne C. Hepatitis C virus seroprevalence in pregnant women delivering live-born infants in North Thames, England in 2012. Epidemiol Infect. 2016;144:627-34.

32. Kopilović B, Poljak M, Seme K, Klavs I. Hepatitis C virus infection among pregnant women in Slovenia: study on 31,849 samples obtained in four screening rounds during 1999, 2003, 2009 and 2013. Euro Surveill. 2015; 20(22). Available online: http://www.eurosurveillance.org/ViewArticle. aspx?Articleld=21144.

33. Lembo T, Saffioti F, Chiofalo B, Granese R, Filomia R, Grasso R, Triolo O, Raimondo $G$. Low prevalence of hepatitis $B$ and hepatitis $C$ virus serum markers in a cohort of pregnant women from Southern Italy. Dig Liver Dis. 2017;49:1368-72

34. Walewska-Zielecka B, Religioni U, Juszczyk G, Czerw A, Wawrzyniak Z, Soszynsk $P$. Diagnosis of hepatitis $C$ virus infection in pregnant women in the healthcare system in Poland. Is it worth the effort? Medicine (Baltimore). 2016;95:e4331.

35. Millbourn C, Lybeck C, Fadl H, Fredlund H, Lindahl K, Duberg AS. Screening for HCV in pregnant women and their partners. J Hepatol. 2017;66:5404-5.

36. Munoz-Gamez JA, Salmeron J, Ruiz-Extremera A. Hepatitis B and C prevalence and epidemiology among women in Spain. Hepatology. 2016; 64:387. 67th Annual Meeting of the American Association for the Study of Liver Diseases: The Liver Meeting 2016. https://www.ncbi.n/m.nih.gov/ pubmed/27696477.

37. Velati C, Romano L, Piccinini V, Marano G, Catalano L, Pupella S, Facco G, Pati I, Tosti ME, Vaglio S, et al. Prevalence, incidence and residual risk of transfusion-transmitted hepatitis C virus and human immunodeficiency virus after the implementation of nucleic acid testing in Italy. a 7-year (2009-2015) survey. Blood Transfus. 2018;16:422-32.

38. Politis C, Kavallierou L, Zervou E, Hatzitaki M, Martinis G, Asariotou M, Richardson C. Surveillance of transfusion-transmitted infections in accepted blood donors in greece. The issue of co-infections. In: 18th International Heamovigilance Seminar, vol. 16; 2018. p. s403.

39. Ireland G, Higgins S, Goorney B, Ward C, Ahmad S, Stewart C, Simmons R, Lattimore $S$, Lee V. Evaluation of hepatitis $C$ testing in men who have sex with men, and associated risk behaviours, in Manchester, UK. Sex Transm Infect. 2017:93:404-9.
40. Vanhommerig JW, van de Laar TJ, Koot M, van Rooijen MS, Schinkel J, Speksnijder AG, Prins M, de Vries HJ, Bruisten SM. Evaluation of a hepatitis C virus $(\mathrm{HCV}$ ) antigen assay for routine HCV screening among men who have sex with men infected with HIV. J Virol Methods. 2015;213:147-50.

41. Cotte L, Cua E, Reynes J. HCV incidence in HIV-infected and in PrEP-using MSM. In: 25th Conference on Retroviruses and Opportunistic Infections (CROI); 2018.

42. Ekeke N, Francis-Graham S, King T, Demma S, Rosenberg W. Improving detection and management of HCV infection in prisons. J Hepatol. 2018;68: S306-7.

43. Patel $\mathrm{S}$, Clarke B, Bird G. Hepatitis B and hepatitis $\mathrm{C}$ virus case finding in a medium security UK prison. In: 2016 Canadian digestive diseases week, Canadian Journal of Gastroenterology and Hepatology; 2016.

44. Casella MI, Ascencao B, Goes AT, Luis NP, Messias AC, Brito AP, Joana S, Pocas J. Characterization of an inmate population followed in an infectious diseases department in the centre of Portugal. In: International Congress of drug therapy in HIV infection, Journal of the International AIDS Society, vol. 19; 2016. p. 7

45. Liberal R, Gaspar R, Andrade P, Coelho R, Tavares J, Morgado R, Macedo G. Hepatologists in jails. A proof of concept for tackling hepatitis $C$ in prisons. In: 82 nd annual scientific meeting of the American College of Gastroenterology, American Journal of Gastroenterology, vol. 112; 2017. p. S599-602.

46. Svendsen T, Skaland M, Zinocker S, Hannula R. Systematic screening in an ongoing cross-sectional epidemiological study on hepatitis $C$ high-risk populations in Trondheim city, Norway. In: International liver congress 2017 - 52nd annual meeting of the European Association for the study of the live, Journal of Hepatology, vol. 66; 2017. p. S415.

47. Lerena SL, Cobo C, Alvarez S, Estebanez-Gallo A, Soler MM, Pallas JR, Echevarria S, Saez A, Aguero J, Chueca N, Pellon R, Cuadrado A, Garcia F, Crespo J. A program of testing and treat intended to eliminate hepatitis $\mathrm{C}$ in a prison. The JAILFREE-C study. In: 67th annual meeting of the American Association for the study of liver diseases. The liver meeting 2016, Hepatology, vol. 64; 2016. p. 460A.

48. Aisyah DN, Shallcross L, Hayward A, Aldridge RW, Hemming S, Yates S, Ferenando G, Possas L, Garber E, Watson JM, et al. Hepatitis C among vulnerable populations. A seroprevalence study of homeless, people who inject drugs and prisoners in London. J Viral Hepat. 2018;25:1260-9.

49. Hope VD, Harris R, McVeigh J, Cullen KJ, Smith J, Parry JV, DeAngelis D, Ncube F. Risk of HIV and Hepatitis B and C Over Time Among Men Who Inject Image and Performance Enhancing Drugs in England and Wales. Results From Cross-Sectional Prevalence Surveys, 1992-2013. J Acquir Immune Defic Syndr. 2016;71:331-7.

50. Hope VD. O-08. The impact of 25 years of sero-behavioural surveillance of blood borne viral infections among people who inject drugs in the United Kingdom. J Viral Hepat. 2015;22:5.

51. Valencia La Rosa J, Ryan P, Alvaro-Meca A, Troya J, Cuevas G, Gutierrez J, Moreno S. HCV seroconversion in a cohort of people who use drugs followed in a mobile harm reduction unit in Madrid. Breaking barriers for HCV elimination. PLoS One. 2018;13:e0204795.

52. Folch C, Casabona J, Espelt A, Majo X, Merono M, Gonzalez V, Wiessing L, Colom J, Brugal MT. High prevalence and incidence of hiv and hcv among new injecting drug users with a large proportion of migrants--is prevention failing? Subst Use Misuse. 2016;51:250-60.

53. Leon L, Kasereka S, Barin F, Larsen C, Weill-Barillet L, Pascal X, Chevaliez S, Pillonel J, Jauffret-Roustide M, LES Y. Age- and time-dependent prevalence and incidence of hepatitis C virus infection in drug users in France, 20042011. model-based estimation from two national cross-sectional serosurveys. Epidemiol Infect. 2017;145:895-907.

54. Weill-Barillet L, Pillonel J, Semaille C, Leon L, Le Strat $Y$, Pascal $X$, Barin F, Jauffret-Roustide M. Hepatitis C virus and HIV seroprevalences, sociodemographic characteristics, behaviors and access to syringes among drug users, a comparison of geographical areas in France, ANRS-Coquelicot 2011 survey. Rev Epidemiol Sante Publique. 2016;64:301-12.

55. Sypsa V, Vickerman $P$, Wiessing L, Malliori M, Hatzakis A. High levels of transmission of HCV infection among people who inject drugs in Greece. J Hepatol. 2017;66:S416.

56. Sheka M, Elefsiniotis I, Patrinos S, Saroglou G. HCV infection in intravenous drug users in Greece during the period January 1997 through December 2007. Arch Hell Med. 2014;31:461-7.

57. Derks L, Gassowski M, Nielsen S, An der Heiden M, Bannert N, Bock CT, Bremer V, Kucherer C, Ross S, Wenz B, et al. Risk behaviours and viral 
infections among drug injecting migrants from the former Soviet Union in Germany. Results from the DRUCK-study. Int J Drug Policy. 2018;59:54-62.

58. Tarjan A, Dudas M, Wiessing L, Horvath G, Rusvai E, Treso B, Csohan A. HCV prevalence and risk behaviours among injectors of new psychoactive substances in a risk environment in Hungary-An expanding public health burden. Int J Drug Policy. 2017;41:1-7.

59. Handanagic S, Bozicevic I, Civljak M, Dominkovic Z, Sevic S, Barbaric J, Nemeth Blazic T, Dakovic Rode O, Begovac J. HIV and hepatitis C prevalence, and related risk behaviours among people who inject drugs in three cities in Croatia. Findings from respondent-driven sampling surveys. Int J Drug Policy. 2016;32:57-63.

60. Kaberg M, Hammarberg A, Lidman C, Weiland O. Prevalence of hepatitis C and pre-testing awareness of hepatitis C status in 1500 consecutive PWID participants at the Stockholm needle exchange program. Infect Dis (Lond). 2017:49:728-36

61. Keegan D, Crowley D, Laird E, Van Hout MC. Prevalence and risk factors for Hepatitis $C$ viral infection amongst a cohort of Irish drug users attending a drug treatment centre for Agonist Opioid Treatment (AOT). Heroin Addict Relat Clin Problems. 2017:19:45-55.

62. Skocibusic S, Martinac M, Arapovic J, Grgic S, Nikolic J, Hasanagic D, Bevanda M, Ravlija J. HBV and HCV serological monitoring among injection drugs users in opiate substitution treatment in Bosnia and Herzegovina. J Infect Dev Ctries. 2016;10:968-72.

63. Svendsen T, Skaland M, Zinöcker S, Hannula R. Systematic screening in an ongoing cross-sectional epidemiological study on hepatitis $\mathrm{C}$ high-risk populations in Trondheim city, Norway. J Hepatol. 2017;66:S415.

64. Nosotti L, Fagetti R, Rocchi L, Khoperia M, Mirisola MC, Testa R, Leonardi C. Prevalence of HCV infection and adherence to DOT therapy in Italian and non-Italian IV drug users in Rome, Italy. Heroin Addict Relat Clin Problems. 2014;16:41-4.

65. Drositis I, Bertsias A, Lionis C, Kouroumalis E. Epidemiology and molecular analysis of hepatitis A, B and C in a semi-urban and rural area of Crete. Eur J Intern Med. 2013;24:839-45.

66. Tarjan A, Dudas M, Gyarmathy VA, Rusvai E, Treso B, Csohan A. Emerging Risks Due to New Injecting Patterns in Hungary During Austerity Times. Subst Use Misuse. 2015;50:848-58.

67. Hope VD, Cullen KJ, Smith J, Jessop L, Parry J, Ncube F. Is the recent emergence of mephedrone injecting in the United Kingdom associated with elevated risk behaviours and blood borne virus infection? Euro Surveill. 2016;21(19). https://doi.org/10.2807/1560-7917. ES.2016.21.19.30225.

68. Rhodes T. Risk environments and drug harms. a social science for harm reduction approach. Int J Drug Policy. 2009;20:193-201.

69. Friedman SR, Rossi D, Braine N. Theorizing "Big Events" as a potential risk environment for drug use, drug-related harm and HIV epidemic outbreaks. Int J Drug Policy. 2009;20:283-91.

70. Hope VD, Eramova I, Capurro D, Donoghoe MC. Prevalence and estimation of hepatitis B and C infections in the WHO European Region. a review of data focusing on the countries outside the European Union and the European Free Trade Association. Epidemiol Infect. 2014;142:270-86.

71. Vickerman P, Martin N, Turner K, Hickman M. Can needle and syringe programmes and opiate substitution therapy achieve substantial reductions in hepatitis C virus prevalence? Model projections for different epidemic settings. Addiction. 2012;107:1984-95.

72. Hagan $\mathrm{H}$, Pouget ER, Des Jarlais DC. A systematic review and meta-analysis of interventions to prevent hepatitis $C$ virus infection in people who inject drugs. J Infect Dis. 2011;204:74-83.

73. Turner KM, Hutchinson S, Vickerman P, Hope V, Craine N, Palmateer N, May M, Taylor A, De Angelis D, Cameron S, et al. The impact of needle and syringe provision and opiate substitution therapy on the incidence of hepatitis C virus in injecting drug users. pooling of UK evidence. Addiction. 2011;106:1978-88.

74. Van Den Berg C, Smit C, Van Brussel G, Coutinho R, Prins M. Full participation in harm reduction programmes is associated with decreased risk for human immunodeficiency virus and hepatitis C virus. evidence from the Amsterdam Cohort Studies among drug users. Addiction. 2007;102:1454-62.

75. Metzig C, Surey J, Francis M, Conneely J, Abubakar I, White PJ. Impact of Hepatitis C Treatment as Prevention for People Who Inject Drugs is sensitive to contact network structure. Sci Rep. 2017;7:1833.
76. Kabiri M, Jazwinski AB, Roberts MS, Schaefer AJ, Chhatwal J. The changing burden of hepatitis $C$ virus infection in the United States. model-based predictions. Ann Intern Med. 2014;161:170-80.

77. Razavi H, Elkhoury AC, Elbasha E, Estes C, Pasini K, Poynard T, Kumar R. Chronic hepatitis $\mathrm{C}$ virus (HCV) disease burden and cost in the United States. Hepatology. 2013;57:2164-70.

\section{Publisher's Note}

Springer Nature remains neutral with regard to jurisdictional claims in published maps and institutional affiliations.
Ready to submit your research? Choose BMC and benefit from:

- fast, convenient online submission

- thorough peer review by experienced researchers in your field

- rapid publication on acceptance

- support for research data, including large and complex data types

- gold Open Access which fosters wider collaboration and increased citations

- maximum visibility for your research: over $100 \mathrm{M}$ website views per year

At BMC, research is always in progress.

Learn more biomedcentral.com/submissions 